See Article page 6.

\section{Commentary: Endovascular therapy of a thoracic aorta mycotic aneurysm: The greatest risk is taking no risk!}

\author{
Julia Merkle-Storms, MD, and \\ Oliver J. Liakopoulos, MD
}

Mycotic aortic aneurysms, also known as infected aneurysms, associated with concomitant mitral valve endocarditis as described in the case report of Zimmermann and colleagues $^{1}$ in this issue of the Journal are rare, but when diagnosed they present a life-threatening disease with a perioperative high mortality of up to $43 \%$. $^{2}$ Usually this special kind of aneurysm arises from bacterial infection of the arterial wall mainly caused by an endocarditis. ${ }^{3} \mathrm{Up}$ to $2.0 \%$ of aortic aneurysms are mycotic. ${ }^{3,4}$ Once the inner wall of the aortic vessel becomes infected, it decays and an aneurysm forms, which is often unstable and highly prone to rupture. Without medical or surgical care, abysmal hemorrhage may occur.

This raises the first question, that is, how to optimally treat mycotic aortic aneurysms due to mitral endocarditis? In general, there are currently no randomized trials for deducing guidelines on the management of mycotic aneurysms. ${ }^{5}$ The diagnosis of mycotic aneurysm is quite difficult due to the fact that the majority of the symptoms are nonspecific. ${ }^{2}$ Like in the presented case report, patients with mycotic aneurysms often have comorbidities that dramatically enhance the risk for open aortic surgery. Therapy usually includes administration of targeted antibiotic therapy and open surgical debridement of the infected aortic tissue following vessel reconstruction. The treatment of the mycotic aortic aneurysm with endovascular stent grafts (ie,

\footnotetext{
From the Department of Cardiothoracic Surgery, Heart Center, University of Cologne, Cologne, Germany.

Disclosures: Authors have nothing to disclose with regard to commercial support. Received for publication Nov 22, 2019; revisions received Nov 22, 2019; accepted for publication Nov 29, 2019; available ahead of print Jan 9, 2020.

Address for reprints: Oliver J. Liakopoulos, MD, Department of Cardiothoracic

Surgery, Heart Center of the University of Cologne, Kerpener Strasse. 62, 50924

Cologne, Germany (E-mail: oliver.liakopoulos@uk-koeln.de).

JTCVS Techniques 2020;1:9-10

2666-2507

Copyright (c) 2019 The Author(s). Published by Elsevier Inc. on behalf of The American Association for Thoracic Surgery. This is an open access article under the CC BY-NC-ND license (http://creativecommons.org/licenses/by-nc-nd/4.0/).

https://doi.org/10.1016/j.xjtc.2019.11.008
}

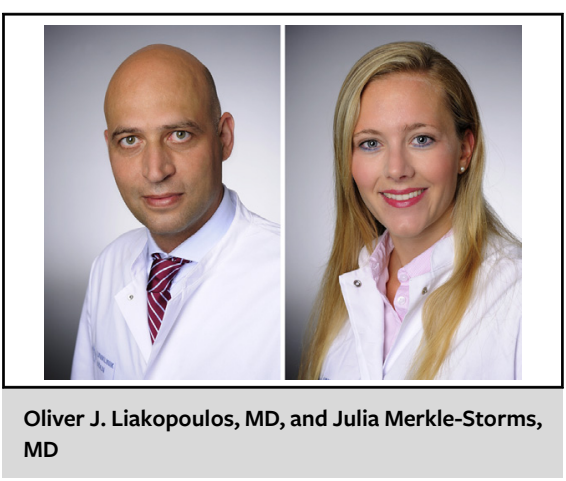

CENTRAL MESSAGE

Endovascular aortic repair

should be considered as a treat-

ment option in patients with

mycotic aneurysm if deemed too

high risk for open surgery.

thoracic endovascular aortic repair [TEVAR]) has emerged as a possible alternative strategy to open surgery, but is still considered to be problematic due to the sustained infection and the inherent risk of a deleterious early or late reinfection of the endovascular graft. ${ }^{6-8}$ Consequently, there is still an ongoing controversy in the current literature whether the less-invasive endovascular treatment options can be truly regarded as an alternative strategy to radical debridement. ${ }^{6-8}$

As demonstrated in the present report by Zimmermann and colleagues, ${ }^{1}$ endovascular repair may be indeed be a suitable option for patients suffering from infected aortic aneurysms and when open surgery seems to be too precarious. The authors present a case with a 78-year-old patient suffering from a thoracic aorta mycotic aneurysm and infective mitral valve endocarditis. Due to severe comorbidities, a staged approach with TEVAR, previous chronic antibiotic treatment, and subsequent mitral valve repair (after 6 months) was chosen, and the patient recovered well. The strength of this report consists in its 2-year follow-up, showing a good recovery of the patient with no reinfection occurring after the first-stage TEVAR treatment.

To sum up, patients with mycotic aortic aneurysms are rare and there are currently no universal surgical treatment guidelines that can be routinely applied to these patients. ${ }^{4,9}$ This present report shows that in patients considered to be inoperable due to significant comorbidities a thorough evaluation for an endovascular approach may be suitable, 
pending on the patient's preoperative condition and infection status. ${ }^{4}$ Considering all these aspects, Zimmermann and colleagues ${ }^{1}$ demonstrated a high emphatic medical sensitivity with their successful staged approach that served the patient in the best possible way.

\section{References}

1. Zimmerman E, Ohami T, Dayal R, Avgerinos D. A successful staged approach for treatment of concomitant mitral insufficiency and mycotic aneurysm. J Thorac Cardiovasc Surg Tech. 2020;1:6-8.

2. Razavi MK, Razavi MD. Stent-graft treatment of mycotic aneurysms: a review of the current literature. J Vasc Interv Radiol. 2008;19(6 suppl):S51-6.

3. Sorelius K, di Summa PG. On the diagnosis of mycotic aortic aneurysms. Clin Med Insights Cardiol. 2018;12. 1179546818759678.
4. Aoki C, Fukuda W, Kondo N, Minakawa M, Taniguchi S, Daitoku K, et al. Surgical management of mycotic aortic aneurysms. Ann Vasc Dis. 2017;10:29-35.

5. Karkkainen JM, Pather K, Tenorio ER, Mees B, Oderich GS. Should endovascular approach be considered as the first option for thoraco-abdominal aortic aneurysms? J Cardiovasc Surg (Torino). 2019;60:298-312.

6. Hirano K, Tokui T, Nakamura B, Inoue R, Inagaki M, Toyoshima H, et al. Hybrid therapy for mycotic aortic aneurysm with stent-graft and video-assisted thoracoscopic debridement. Ann Vasc Dis. 2019;12:69-73.

7. Sorelius K, Mani K, Bjorck M, Sedivy P, Wahlgren CM, Taylor P, et al. Endovascular treatment of mycotic aortic aneurysms: a European multicenter study. Circulation. 2014; 130:2136-42.

8. Rasoul S, Jaspers RM Jr, van Wijngaarden J. Mycotic aneurysm of the aortic arch. Neth Heart J. 2011;19:397-8.

9. Sorelius K, Budtz-Lilly J, Mani K, Wanhainen A. Systematic review of the management of mycotic aortic aneurysms. Eur J Vasc Endovasc Surg. 2019;58:426-35. 